\title{
Novel application of a predictive skill retention model to technical VLE content production skills among Higher Education teachers: A case study
}

\author{
Marie Cahillane, Piers MacLean, and Victoria Smy
}

Applied Psychology Group, Centre for Electronic Warfare, Information, and Cyber, Cranfield University, Defence Academy of the UK, Shrivenham, SN6 8LA

Email: \{m.cahillane/p.j.maclean/v.smy\}@cranfield.ac.uk

Telephone: $0179378\{5415 / 5281 / 5737\}$

Corresponding author: Dr Marie Cahillane

Biographical notes:

Dr Marie Cahillane (CPsychol) is Head of the Applied Psychology Group at Cranfield University, with over nine years' experience in applying principles in cognitive psychology to Human Factors research projects related to learning and development. Marie has applied her expertise in human cognition and quantitative research methods to various defence research projects examining but not limited to skills acquisition and retention, technology supported learning, objective metric design and human interaction with complex systems. Recent externally funded research has involved understanding the psychological mechanisms that underpin skill retention across various contexts. Marie was awarded her $\mathrm{PhD}$ in Cognitive Psychology by the University of the West of England, an MSc in Research Methods in Psychology from the University of Bristol, and a BSc (Hons) in Psychology (Major) with Sociology from Bath Spa University.

Piers MacLean is a lecturer within the Applied Psychology Group at Cranfield University. Since 2011 he has worked alongside Dr Cahillane contributing to Defence Human Factors research projects. His interests lie in acquisition and retention of complex skills, cognitive agility, and the application of cognitive control to task achievement. He is currently undertaking a $\mathrm{PhD}$ investigating the effects of cognitive load and disruption of executive function on complex perceptual-motor skills. Piers has an MSc by Research in Learning Design from Cranfield University and a BA (Hons) in Learning Technology and Research from Anglia Ruskin University. 
Dr Victoria Smy (CPsychol) is a Lecturer in Human Cognition within the Applied Psychology Group at Cranfield University. Research specialities include problem-solving at the humancomputer-interface, judgment and decision making in complex environments, and training design (including attitudes, analysis, design, delivery, and assessment).Victoria obtained a $\mathrm{PhD}$ in Cognitive Psychology, an MSc in Occupational Psychology, and a BSc in Psychology from Cardiff University. 


\section{Novel application of a predictive skill retention model to technical VLE content production skills among Higher Education teachers: A case study}

Periods of no practice in performing a technical procedure may impact on the retention of the procedural skills required to produce VLE content. This exploratory paper reports a case study into the application of a validated skills retention model, the User Decision Aid (UDA). Use of the UDA results in a series of indicative retention rates predicting how long the procedures required to carry out Virtual Learning Environment (VLE) content production tasks will be remembered. Considerable variability in retention rates for differing VLE content production tasks was indicated. The study reveals that improvement in predicted VLE content production skills retention rates may be observed when a quality job aid is available and the mental processing complexity resulting from conducting VLE tasks is reduced. Outputs from this research can inform the design of VLEs, lead to the development of targeted training for teaching staff, and the better design of effective resources in order to mitigate skills fade in VLE content production tasks.

Keywords: VLE content production; procedural skills retention; VLE system design, User Decision Aid; job aids; refresher training; mental processing.

\section{Introduction}

Many Higher Education (HE) institutions are implementing technology to deliver teaching content and support learning (Glenn, 2008; Walker, Voce, \& Jenkins, 2016; Walker, Voce, Nicholls, et al., 2014). Within HE Virtual Learning Environments (VLEs) technology has offered a number of advantages. Benefits to teaching provision include reaching wider audiences, introducing flexibility in the scheduling and pace of learning, and improving teaching auditability and standardisation (Cahillane, Smy, \& MacLean, 2016). In addition, a technologically-driven e-learning strategy raises an organisation's visionary profile (King \& Boyatt, 2014) and has been shown to have an impact on student satisfaction (Cassidy, 2016) and retention (Heaton-Shrestha, May, \& 
Burke, 2009). It comes as no surprise that acquisition and retention of the procedural skills needed to produce VLE content, is an enabler in the effective use of VLEs in support of student learning (e.g., Golden, McCrone, Walker, \& Rudd, 2006; Rogers, 2003). However, not only are many VLEs not implemented with pedagogical principles and teacher experience in mind (e.g., Beetham \& Sharpe, 2007), little consideration is given to the impact that VLE technology has on the skills required of the teaching staff, in particular those that underpin VLE content production tasks. These tasks require procedural skills i.e, retrieval from memory of a series of sequential actions. A body of research in cognitive psychology demonstrates a greater rate of decay for procedural skills over extended periods of non-use (e.g. Annett, 1979; Goodwin, 2006; Goodwin et al., 2007; Sanders, 1999; 2001) compared to other skills such as perceptual-motor skills (Patrick, 1992; Swezey and Llaneras, 1997). Furthermore, a key determinant of memory for procedural skills concerns the number of steps involved, with the finite span of immediate memory being around seven items (Miller, 1956). Despite this, there are often high expectations of staff technical abilities with respect to implementing technology within their teaching provision (Attwell \& Hughes, 2010). Support, training, and ongoing development are needed to address this as are the development of systems designed to reduce cognitive load resulting from having to retrieve too many procedural steps from memory (Kim \& Ritter, 2015; Kim, Ritter, \& Koubek, 2013; West, Farmer, \& Wolff, 1991; Wilson, 2002). Where system complexity in terms of the number of procedural steps cannot be minimised, job aids can provide an appropriate level of support. Audio-visual materials combined with text are found to be suitable for a wide range of teaching staff (Mayer, 2003; Moreno \& Mayer, 2007).

Once suitably trained, the rate of decay of the acquired procedural skills underpinning VLE content production should also be taken into account. To the 
authors' knowledge, procedural skills retention with regards to teachers' VLE content production tasks has not been investigated. This case study aims to go some way towards bridging this gap in knowledge by outlining the state of the science with respect to the retention of procedural skills, and presenting a novel application of a predictive skills retention model. The results of such an approach may be used for targeting and scheduling appropriate refresher training to promote the retention of procedural technical (as opposed to the intellectual and pedagogical) competencies within teaching staff.

Whilst much of the educational technology literature has focused on the pedagogical knowledge and skills required for effective learning (e.g. Balla, 2009; Ha \& Kim, 2014), the cognitive psychology literature provides a body of relevant empirical evidence demonstrating procedural skills are highly susceptible to decay after periods of non-use (e.g. Arthur, Bennett, Stanush, \& McNelly, 1998; Cahillane \& Morin, 2012; Goodwin, Leibrecht, Wampler, et al., 2007; Sabol \& Wisher, 2001; Wisher, Sabol, \& Ellis, 1999). Such skills are required to produce learning content in VLEs and it follows that the decay of the procedural skills underpinning VLE content production tasks could affect student learning because teaching staff might only use tools and techniques for which they remember the procedural steps involved. Babić and colleagues (Babić \& Bubaš, 2015; Babić, Čičin-Šain, \& Bubaš, 2016) outline a number of crucial factors associated in determining whether teachers adopt technology in their practise. These include perceived self-efficacy in using the technology, ease of technology use, and the degree of anxiety towards technology. A recent study found perceived ease of use is related to the intentions and actual behaviour of staff using VLEs (Rienties et al., 2016), with staff unlikely to use VLE content production tasks perceived as more complex and difficult to learn. In Rientes et al.'s study, more complex VLE content production tasks, 
as perceived by Subject Matter Experts (SMEs), included 'create a discussion forum thread' and 'create an assignment' (e.g., quiz or essay assessment). Although, Rientes et al.'s study did not consider the retention of the ability to carry out these perceived complex tasks acquisition and retention are known to be linked (MacLean \& Cahillane, 2015). Thus, it can be argued that tasks which are perceived as more difficult to learn are likely to be more difficult to remember.

The Institute of Learning survey of teaching staff (2010) stated that approximately a third of teachers participating in the survey reported not being confident in the use of technologies to support their teaching provision, and over half believed that they would benefit from training in the use of teaching technologies. As such, the provision of support and training in content production tasks should lead to greater teacher engagement through boosting self-efficacy and reducing computing anxiety. Optimal VLE support and training must take into account the procedural skills, in addition to pedagogical knowledge, required to produce VLE content along with consideration of the various rates at which such skills may decay (Bonsall, 2012; Bryant \& Angel, 2000). For instance, VLE content production tasks often involve a combination of the following activities: designing and generating learning activities in support of summative and formative assessment (e.g., quizzes); accessing and commenting on submitted assignments; and, posting learning material. Proficient performance of such activities is underpinned by procedural skills which involve the successful retrieval from memory of a number of discrete steps and facts. Whilst VLE task analysis can be used effectively to outline the procedural skills and performance standards required to guide training outcomes, there is a need to understand and predict the retention of VLE content production tasks in order to appropriately plan for and mitigate skill fade through refresher training. Understanding procedural skills retention 
would also inform the design of future VLEs to mitigate skills degradation. In the following discussion, a validated (see discussion below) predictive skills retention model fit for this purpose is outlined.

\section{Predicting procedural skills retention}

The User Decision Aid (UDA) model was developed by the United States (US) Army Research Institute (ARI) to predict skill retention and provide unit commanders and trainers with an evidence-base to inform the scheduling of refresher training (Rose, Manning, Radtke, \& Ford, 1984; Rose, Radtke, Shettel, \& Hagman, 1985). The UDA was developed using 54 military procedural tasks (Rose, Czarnolewski, et al., 1985) as most military tasks involve a procedural skill component. The model is theoreticallybased and includes 10 of the most important task-related factors known to moderate skill retention, according to the psychological literature (see Table 1). The UDA has been found to have high validity and reliability (MacPherson, Patterson, \& Mirabella, 1989; Rose et al., 1984; Rose, Czarnolewski, et al., 1985) and its curves resemble procedural skills decay in the psychological literature (e.g. Wixted \& Ebbesen, 1991). The UDA can therefore be applied to VLE content production tasks with reasonable confidence.

[Table 1 near here]

The UDA forms a survey-based task rating method, which can be applied by SMEs wishing to rate the characteristics of individual tasks in order to generate indicative retention curves. Whilst subsequent research has identified other factors which influence retention for example, frequency of application and the contextualisation of the training environment to the performance context (see Cianciolo, Crabb, Schaefer, et al., 2010), to date the UDA is the most developed scientific 
predictive model of skills retention and has also received validation (see Rose, Czarnolewski, Gragg, et al., 1985). In addition to being applied to field artillery tasks the UDA has been successfully used with a number of other military procedural tasks, including those performed by combat engineers and carpentry specialists (Kern, Wisher, Sabol, \& Farr, 1993), and vehicle mechanics (Macpherson, Patterson, \& Mirabella, 1989). Macpherson et al. argue that given the UDA's high reliability and validity the model provides a critical and cost-effective supplement to empirical studies since it allows SME's to quickly evaluate large numbers of tasks. Furthermore, Macpherson et al's. application of the UDA found that SMEs agreed on task characteristic ratings for the majority of the tasks surveyed.

The UDA does not predict individual skill or task retention scores. Rather it predicts the percentage of staff members within an organisation that are able to conduct a procedural task successfully to a pre-defined standard, after a period of time has elapsed since the task was last performed. The retention curves generated by the UDA predict retention following up to 12 months of no practice in performing the task. The retention curves generated are based on the assumption that $100 \%$ of staff reached the appropriate performance standards at the end of their last training session.

\section{Aims and objectives}

To our knowledge, no evidence exists regarding procedural skills retention in relation to VLE content production tasks required by HE teaching staff utilising VLEs. An empirical model of procedural skill fade, guided by principles derived from cognitive science, would enable such institutions to understand, develop and support the procedural skills required for VLE content production. To address this gap in the literature, an exploratory case study applied the UDA predictive skills retention model. 
Although initially developed for military research, the UDA was designed as a psychological model for predicting skill fade for procedural tasks. Whilst the underpinning data was collected in the context of military procedural task performance, we argue that it remains relevant as a novel methodology that is applicable to the current study because VLE content production tasks are underpinned by generic procedural skills. The present case study is bound in scope to addressing the procedural and not pedagogical aspect of VLE content production; the procedural aspect is an enabler to the pedagogical aspect. Further justification for application of the UDA lies in its uniqueness. It is the only fully developed predictive model of skill fade drawn from a body of empirical data on actual performance. The following section outlines the methodological approach adopted.

\section{Method}

\section{Participants}

Given the UDA method involves the rating of task characteristics as opposed to being a psychometric measure of individual characteristics, the sample size required was determined by the number of SMEs involved in supporting flexible and distance learning through the use of VLEs within the University used for this case study. The number of participants was therefore limited to two SMEs who met this requirement. These SMEs had approximately 25 years of collective experience in the administration and use of proprietary, bespoke, and open-source VLEs met this requirement. In the 2014 Universities and Colleges Information Systems Association survey of the use of technology in education, $100 \%$ of the responding institutions used a VLE. The most popular VLE was Moodle closely followed by Blackboard (Walker et al., 2014). Although the University involved in this case study currently uses both of these VLEs, 
for the purposes of this study Moodle version 2.5.9 was used as the point of reference. The features referred to are commonly encountered in a wide variety of VLEs but may be named differently. Nonetheless, the use of these features across almost all VLEs is underpinned by procedural skills.

\section{Interview design}

The UDA rating form was developed to enable the prediction of skills retention for military tasks and consists of 10 questions targeting the assessment of factors known to moderate procedural skill retention. Each question is multiple-choice, requiring the selection of one response from a prescribed set. To aid in the interpretation of prescribed responses, each was accompanied by a verbal description of its intended meaning. Responses were also weighted and scored, with lower scores denoting greater difficulty in retaining task competence. Once the rating form has been applied, following the relevant skip logic (see Table 1), response scores can be totalled. The total score for each task is then matched to the corresponding closest score in Rose et al.'s (1985) performance prediction table. The numbers within this prediction table represent the expected percentage of a work force able to perform a task correctly after up to 12 months of no practice. The output of the analysis is retention curves for each task which aid in the comparison and visualisation of the procedural skill retention.

In addition to its constituent questions and prescribed responses, Rose, Radtke et al. (1985) developed contextualised worked examples to rapidly orient and familiarise SMEs with the process of applying the UDA model to relevant, procedural tasks. In order to afford our e-learning SMEs similar benefits, adapted worked examples were developed to reflect the present VLE context. For instance, 'assembling the M16 rifle' was replaced with 'creating a pop-up window for a book item'. Although at first glance 
these are very different tasks, the demonstrated application of the prescribed UDA responses and underlying processing requirements were unaltered. Where military terms such as 'soldier' were present in the original UDA form, these were replaced with context-relevant terms such as 'individual' or 'staff member'.

\section{Procedure}

The VLE SMEs conducted a task analysis to decompose content production activities within VLEs into their constituent tasks each of which is procedural in nature. A total of 16 tasks, which describe key VLE management, use, and content organisation activities, were identified. In addition, standards indicative of effective task performance were ascertained. Facilitated by the research team, the SMEs applied the UDA rating form to assess the predicted skill retention aligned to each task. UDA questions were applied in the appropriate order given the relevant skip logic. The research team guided the SMEs in their interpretation of all possible response selections using response descriptions and outlining the associated weighting and values assigned to each response. Where SMEs initially disagreed on response selection, consensus was obtained through SME discussion. This was preferable to calculating arithmetic means, as only the weighted response scores stipulated in the UDA model were acceptable, due to weighted differences reflecting either factual matters (e.g., the presence or absence of a job aid) or qualitative differences in judgement (e.g., 'how good is the job aid?'). The total time taken to conduct the task analysis and apply the UDA rating form with SMEs was three hours. SME input was not sought for comparative analysis of UDA ratings or the generation of skill retention curves, reported in the following section.

\section{Results and discussion}

The VLE content production task analysis revealed 16 unique tasks, all of which were 
deemed by the SMEs as representative of the procedural skills underpinning competence in using the VLE. Of the 16 tasks, UDA rating scores ranged from 84-179, with a mean score of 148 (SD 25). With respect to the application of UDA question skip logic, of the nine tasks that were supported by a job aid (Question 1), eight (89\%) were categorised as "excellent" by the SMEs (Question 2). Of the seven tasks not supported by a job aid, all entailed more than one procedural step (Question 3). SMEs indicated that all tasks had mental processing requirements (Question 7). Of note is that when considering UDA question ratings there was no variation, across all tasks, for two questions (Question $6 \& 10$ ). As such, all tasks were perceived by the SMEs to have "no time limit", and "small" motor control requirements.

[Figure 1 near here]

Analysis of the performance prediction table (Rose et al., 1985) with respect to the SME UDA ratings resulted in a series of indicative retention curves as shown in Figure 1. Considerable variability is demonstrated. A clear distinction can be made between those tasks whose underpinning procedural skills fade rapidly (11 tasks) versus tasks that are predicted to fade very little ( 5 tasks). Indeed, the UDA retention algorithm predicts that less than $10 \%$ of tutors will be able to perform the 'rapid fade procedural tasks' successfully (i.e., without errors or further training) after 12 months of no practice. For illustrative purposes, comparability and continuity across tasks, differences in predicted refresher training intervals for the e-learning content organisation tasks were defined by the point at which $50 \%$ of the work force who are not utilising the relevant skills are predicted to no longer be able to perform the task successfully (i.e., without errors, practice or further training). Table 2 indicates the predicted refresher intervals for all VLE organisation tasks. The mean refresher interval for rapid fade tasks was just 11.18 weeks (SD 4.26). 
[Table 2 near here]

Job aids, including but not limited to quick reference guides, mnemonics, and technical manuals and publications act to reduce human memory capacity load and enhance retention of information by externalising the steps that are required for successful task performance (Bryant \& Angel, 2000; Rose, Czarnolewski, et al., 1985; Stothard \& Nicholson, 2001). Less apparent forms of job aid are encountered in technology design where functions are set up such that the steps have to be performed in a particular order. At the time of conducting this study, no job aid was available to assist staff in performing seven of the VLE content production activities, as indicated in Table 2. Mental processing requirement complexity refers to the difficulty of the thought processes an individual must apply whilst performing a task. Such thought processes are often described as judgment, reasoning, analysis, decision making and problem solving. A task is characterised by very complex mental processing requirements if it requires rapid decisions based on complex technical information in uncertain and stressful situations (Rose, Czarnolewski et al., 1985).

As indicated in Table 2, all slow fade tasks incorporated an "excellent" job aid which externalised memory for task procedures, and "simple" mental processing requirements. In contrast, rapid fade tasks were characterised by the lack of either or both of these task characteristics. The task Setting up a quiz which was predicted to fade the most comprised complex mental processing requirements, no job aid, and involved recalling over ten procedural steps. Other rapid fade tasks such as Using Turnitin, Using Grademark, and Managing a folder on a page encompassed an excellent job aid but retained complex mental processing requirements, whilst Adding a URL/HTML comprised of simple mental processing requirements, a small number of procedural steps (between 2 and 5) but no supporting job aid. 
The extent to which the availability of an excellent quality job aid and a simplification of the mental processing requirements would improve the predicted level of retention of the rapid fade VLE content production tasks was examined. The amended refresher intervals displayed in Table 2 clearly demonstrate that making a quality job aid available for tasks where these are currently lacking and simplifying the complexity of the mental processing required for their undertaking improves retention intervals for all 11 rapid fade tasks. However, whilst most of the amended tasks would be predicted to have improved retention periods of 48 weeks or more, Setting up a quiz still exhibits a relatively low retention period of just 16 weeks. It seems therefore, that amending the mental processing requirements and providing an excellent job aid would enable the scheduling of refresher training every 12 months to support the retention of the knowledge and skills underpinning VLE content production, with the exception of Setting up a quiz. In order to support Setting up a quiz shorter refresher training intervals, or the provision of further support tools (e.g., video tutorials) would be required to extend skill retention periods. In addition, VLE design could support Setting up a quiz if functions are set up such that the number of steps which have to be performed in a particular order are reduced (West et al., 1991; Wilson, 2002; Kim \& Ritter, 2015).

\section{General discussion}

The findings of the present study indicate that it is possible to use the UDA predictive skills retention model as a tool for differentiating and prioritising key procedural VLE content production tasks. Application of the UDA demonstrated variability in retention rates for a range of VLE content production procedural tasks, which enabled the categorisation of rapid as opposed to slow fade tasks. Rapid fade tasks include tasks incorporating procedural skills in support of teacher-student 
interaction (e.g., Using news forums/Quick mail for communications), the provision of feedback during formative and summative assessment (e.g., Using Grademark / Turnitin), and in support of the production of VLE learning content (e.g., Adding a book activity and Setting up a quiz). The predicted rapid fade for these procedural VLE content production tasks is supported by extant performance data from relevant empirical research. Cahillane and Morin (2012) demonstrated that extended periods of non-use of a digital information management system impacts on the retention of the digital procedural skills required to use the system effectively. Cahillane and Morin's experimental trial found that more than $55 \%$ of personnel fell below the criterion level of performance at their first assessment, which was taken between one and nine weeks after their assessment at the end of initial training. Other empirical research also supports the prediction of a significant decline in the level of retention found for procedural skills after a period of no practice (Arthur, et al., 1998; Goodwin et al., 2007; Sanders, 1999; Wisher et al., 1999). In contrast, tasks predicted to fade much more slowly over a period of no practice represented basic procedural functional activities used to present pre-designed VLE content (e.g., Managing page sections and Displaying and hiding individual items on a page) or allow students to interact with their peers (Setting up a discussion forum). It should be noted, however, that there is an absence of empirical evidence regarding retention of VLE procedural tasks in the literature. However, the available empirical evidence regarding the decay of procedural skills across different contexts indicates such generic skills underpin context specific multi step sequentially organised tasks, such as those required by teaching staff to produce learning content within VLEs.

The rapid fading of the procedural skills underpinning many VLE tasks is of crucial importance when determining how to schedule refresher training. If academic 
staff cannot implement those content production tasks which enable the generation and delivery of learning content, this may result in VLEs being used sub-optimally. Further still, should skill fade reduce the self-efficacy of teaching staff, there may be further implications for the motivation of teaching staff and their perceptions towards VLE usability when choosing to adopt or engage with VLEs (e.g., Babić \& Bubaš, 2015; Babić et al., 2016, Rienties et al., 2016).

Two notable task characteristics impacted upon predicted skill retention rates. The absence of a quality job aid describing how to perform the task and the complexity of mental processing requirements, either individually or combined, distinguished slow from rapid fade VLE tasks. Predicted retention rates of those tasks most susceptible to skill fade was shown to be improved if a quality job aid was available for use while performing the task. Quality job aids externalise memory for key task facts and principles and also prompt the sequential ordering of necessary task steps. Job aids should be easily located. Those that incorporate multiple sources of information in disparate locations should be avoided. However, given the number of VLE tasks (i.e. 16) listed in this case study, and noting that other VLEs may potentially involve more, a multitude of job aids may not necessarily be practical and may inadvertently place a further burden on teaching staff who have to remember where to find the job aid relevant to the task. An alternative to refresher training and the provision of job aids is to design VLEs so that the load on human memory is minimised. To address the limited capacity of human memory, systems need to reduce a user's cognitive load by putting information onto the system (Wilson, 2002). The skills required to operate systems which rely more on knowledge retrieval from memory (knowledge-in-the-head) fade more and are more difficult to re-learn after periods of non-practice than those which rely more on interaction with the system (knowledge-in-the-world). This indicates that a 
well-designed menu driven system can help the user to perform a procedural task by placing less demand on working memory (Kim \& Ritter, 2015). Designers often use methods such as advance organisers, matrices and hierarchical relationships to help users relate new information provided by the system to existing knowledge stored in memory (West et al., 1991).

The reduction of task mental processing requirements (task complexity) is hard to mitigate unless the underpinning knowledge, skills, and attitudes (KSAs) that enable proficient task performance to an agreed standard are accurately and operationally defined (MacLean \& Cahillane, 2015). The task analysis for VLE content production used for the purposes of this study only provided a descriptive summary of the sequence of steps to be undertaken and the principles to be memorised. As such, no targeted recommendations can be made as to how to decrease VLE task mental complexity. However, there is some indication that a reduction in mental processing requirements could be achieved by teaching staff to internalise decision making principles and techniques (Kim, Ritter, \& Koubek, 2011).

Amended VLE task refresher intervals, factoring in the provision of an excellent job aid and a reduction in mental processing requirements resulted, in most cases, in a retention period of $48+$ weeks. A notable exception was the amended refresher interval for Setting up a quiz that fell considerably short of this mark at 16 weeks. As such, it is recommended that efforts be made to reduce mental processing requirements and produce quality job aids that support task performance and enable the provision and scheduling of appropriately spaced refresher training at approximately every 52 weeks for staff who have not practiced the VLE content production task within the past year. Additional interventions may be necessary to support those staff wishing to utilise quizzes within their VLE content provision. Here the use of audio-visual instructor 
videos and screencasts could be used as job aids to provide helpful task hints and principles (e.g. Moreno \& Mayer, 2007; Rienties et al., 2016). However, it is not expected that such interventions would act to eliminate all errors and set-backs in VLE quiz production.

\section{Limitations of the UDA}

The conclusions drawn presently are limited by a number of factors that are now addressed. Firstly, the UDA rating form lacks a large evidence base concerning its predictive accuracy. To our knowledge, only one study has compared UDA predicted scores to actual performance scores at multiple time intervals (i.e., 2, 5, and 7 months), although this study did include a number of investigations of different procedural tasks (Rose, Czarnolewski, et al., 1985). Here the UDA was found to be effective at predicting retention across several military tasks within a field artillery context. The predicted UDA retention curves for these tasks were fairly consistent with trends in actual performance data (observed during live task execution). An observation which was also supported by more recent empirical performance data (Cahillane and Morin, 2012). However, in comparison to the actual performance data across all of the tasks examined by Rose, Czarnolewski, et al, the UDA curves predicted that a lower proportion of soldiers would be able to perform the task successfully than was the case at 2 months ( $5 \%$ lower). At other retention intervals the difference between predicted and actual performance was as great as 30 percent for some tasks, a difference which increased over longer retention intervals. This suggests that the UDA model may be pessimistic in its projected prediction of skill fade across different time intervals, such that the decay rate is potentially predicted to be somewhat worse than might be observed if actual performance data were collected. The potential over estimation of the 
level of skills retention by the UDA has important implications for its application to elearning content organisation on VLEs when considering refresher training intervals. Although the UDA's forward projections of skill fade are potentially pessimistic, it can be argued that they indicate the 'worst case scenario', which, if considered along with other factors known to influence skills retention, can help inform refresher training decisions.

As just indicated, a second limitation of the UDA is that it does not account for known moderators of skill retention, including the level at which individuals originally acquired knowledge and skills during initial training (e.g., overlearning; Sabol \& Wisher, 2001) and the cumulative effect of practice on retention (Cianciolo et al., 2010). For instance, research has shown that, at least in the short-term, knowledge and skills that are acquired to a higher level tend to decay at a slower rate compared to skills acquired after one demonstration of accurate performance (Driskell, Cooper, \& Moran, 1994; Sabol \& Wisher, 2001). Moreover, individual differences in level of original learning have been found to predict skills retention to a higher degree than do individual differences in forgetting rates across skills, including perceptual motor and procedural skills (Swezey \& Llaneras, 1997). Consequently, the predicted rate of skills fade may well be more accurate should the effects of initial skill level and cumulative practice be factored into the UDA ratings.

A final limitation of the present application of the UDA is the change in context between its development for military applications and its present use in an online educational context. Military training contexts are high-pressure environments whereby set levels of performance, both mental and physical, are to be achieved within given timeframes in order to be considered competent at one's job. In contrast, HE teaching staff, engaging with VLEs to support/supplement teaching provision, do not experience 
such pressures. VLE organisation tasks do not require extensive levels of physical movement. In addition, engaging with some VLE organisation tasks may be undertaken entirely at the discretion of the individual staff and are conducted outside of set time frames. Indeed, performance of VLE organisation tasks may only be mandated for those involved in providing summative and formative course assessment. Such contextual differences may explain why two of the UDA rating scales (perceptions of time limits and motor control requirements; Questions 6 and 10 respectively) showed no discriminative power when applied to VLE organisation tasks. Future development of the UDA model should aim to address the contextual relevance of all UDA rating questions.

\section{Conclusions}

Application of the UDA predictive skills retention model indicated variability in retention rates for VLE content production tasks. In particular, tasks representing components of formative and summative assessment which support learning through interaction and feedback were predicted to be highly susceptible to skills fade. During training, having a quality job aid available for these procedural tasks would help optimise their retention, since the memory requirement becomes situated externally within the job aid. Emphasis should also be placed on encouraging staff to be able to locate and use such resources. The complexity of task-related mental processing requirements might also be reduced by instructing staff how to reason and make decisions regarding production of content within VLEs. This should enable the cognitive processes underpinning such tasks to become internalised and thus more representative of simple mental processing requirements (e.g. Kim et al., 2011).

Although beyond the scope of this exploratory case study, it appears that the use of VLE in general is growing in response to an increase in online learners (e.g. Balla, 
2009). Moreover, various initiatives to increase the number of online courses are reported in the media. At the time of writing, the University of London announced its first fully fledged online undergraduate degree and news coverage indicates other institutions will follow suit to remain competitive (Coughlan, 2018). This suggests that the requirement to understand the cognitive aspects of the technical skills required to produce online learning content will be amplified alongside pedagogical considerations.

The findings of this exploratory case study point to a requirement for empirical research into the retention of procedural skills in VLEs. Actual performance data contextualised to VLEs would provide the evidence base to inform recommendations going forward. Hence, the next step for future research will be to compare task ratings allocated using the UDA with actual performance data in order to validate the UDA indicative retention intervals in the context of VLE content production tasks. A case could then be made for incorporating skill fade mitigation planning in VLE system design, training, and resources.

\section{References}

Annett, J.(1979). Memory for skill. In M. M. Gruneberg \& P. E. Morris (Eds.), Applied problems in memory. London: Academic Press.

Arthur, W. Jr., \& Bennett, W. Jr., Stanush, P.L., \& McNelly, T.L. (1998). Factors that influence skill decay and retention: A quantitative review and analysis. Human Performance, 11, 57-101.

Attwell, G., \& Hughes, J. (2010). Pedagogic approaches to using technology for learning - Literature review. Lifelong Learning UK publication CC/01 2011/01.

Babić, S., \& Bubaš, G. (2015). Assessment of competencies of online teachers: pilot study and survey evaluation. In eLearning 2015-6th International Conference on e-Learning. Retrieved 02.08.2016 from, http://econference.metropolitan.ac.rs/files/pdf/2015/26-Snjezana-Babic-GoranBubas-Assessment-of-competencies-of-online-teachers-pilot-study-and-surveyevaluation.pdf 
Babić, S., Čičin-Šain, M., \& Bubaš, G. (2016, January). A study of factors influencing Higher Education teachers' intention to use e-learning in hybrid environments. In Computers in education (CE). Retrieved 02.08.2016 from, http://docs.miproproceedings.com/ce/ce_43_3994.pdf

Balla, A. (2009). Designing Pedagogical Learning Environment. International Journal of Advanced Science and Technology, 6, 1-14.

Beetham, H., \& Sharpe, R. (Eds.). (2007). Rethinking pedagogy for a digital age. London: Routledge.

Bonsall, K. (2012). Non-technical skills for rail: A list of skills and behavioural markers for drivers with guidance notes. RSSB Report. Research Programme Operations and Management.

Bryant, D. \& Angel, H. (2000). Retention and fading of military skills: Literature review. Guelph, Ontario: Human systems Incorporated. (PWGSC Contract No W7711-9-7539/001/TOR).

Cahillane, M., Smy, V., \& MacLean, P. (2016). A case study of the barriers and enablers affecting teaching staff e-learning provision. In, Proceedings of the International Conference on Information Communication Technologies in Education, Rhodes, Greece. (in press)

Cahillane, M.A., \& Morin, C. (2012). Skills retention in a complex battlefield management system. Journal of Battlefield Technology, 15 (1), 65-72.

Cassidy, S. (2016). Virtual Learning Environments as mediating factors in student satisfaction with teaching and learning in Higher Education. Journal of Curriculum and Teaching, 5(1), 113-123.

Cianciolo, A.T., Crabb, B.T., Schaefer, P., Jackson, S. \& Grover, J. (2010). Sustainment of individual and collective future combat skills: Modelling and research methods (ARI Research Report 1918). US Army Research Institute for the Behavioral \& Social Sciences. Arlington, VA.

Coughlan, S. (2018, March 6). University offers science degree online for $£ 5,650$ per year. $B B C$ News. Retrieved from http://www.bbc.co.uk.

Driskell, J., Copper, C., \& Moran, A. (1994). Does mental practice enhance performance? Journal of Applied Psychology, 79 (4), 481-492.

Glenn, M.(2008).The future of higher education: How technology will shape learning. A report from the Economist Intelligence Unit Sponsored by the New Media 
Consortium. The Economist. Retrieved from:

https://files.eric.ed.gov/fulltext/ED505103.pdf

Golden, S., McCrone, T., Walker, M., P Rudd. (2006). Impact of e-learning in Further Education: Survey of scale and breadth. National Foundation for Educational Research. Research Report RR745.

Goodwin, G., Leibrecht, B., Wampler, R.., Livingston, S., \& Dyer, J. (2007). Retention of selected FBCB2 operating skills among infantry captains career course (ICCC) students. (1872). US Army Research Institute for the Behavioral \& Social Sciences. Arlington, VA.

Ha, M., \& Kim, H. (2014). E-Learning Education for Academic Literacy in ComputerMediated Communication. International Journal of Software Engineering and Its Applications, 8(1), 107-118.

Haydn, T. (2008). Teacher education and ICT: some points for consideration from the UK. Retrieved 04.08.2016 from, https://www.researchgate.net/profile/Terry_Haydn/publication/238107103_Teac her_education_and_ICT_some_points_for_consideration_from_the_UK/links $/ 5$ 3eb34200cf2dc24b3cea53f.pdf

Heaton- Shrestha, C., May, S., \& Burke, L. (2009). Student retention in Higher Education: what role for virtual learning environments? Journal of Further and Higher education, 33(1), 83-92.

Kern, R., Wisher, R., Sabol, M., \& Farr, B. (1993). Reacquisition of Skill by Combat Engineers Mobilized from the Individual Ready Reserve (Research Report 1667). U.S. Army Research Institute for the Behavioral and Social Sciences. Alexandria, Virginia.

Kim, J., Ritter, R., \& Koubek, R. (2013). An integrated theory for improved skill acquisition and retention in the three stages of learning. Theoretical Issues in Ergonomics Science, 14 (1), 22-37.

Kim, J.W., \& Ritter, F.E. (2015). Learning, Forgetting, and Relearning for Keystrokeand Mouse-Driven Tasks: Relearning is Important. Human Computer Interaction, 30(1), 1-33.

King, E., \& Boyatt, R. (2014). Exploring factors that influence adoption of e- learning within Higher Education. British Journal of Educational Technology, 46(6), 1272-1280. 
MacLean, P., \& Cahillane, M. (2015). The human factor in learning design, research, policy, and practice. International Journal of Information and Learning Technology. 32(3), 182-196.

Macpherson, D., Patterson, C., \& Mirabella, A. (1989). Application of ARI Skill Retention Model to wheel vehicle maintenance tasks (ARI Report No. 1538). U. S. Army Research Institute for the Behavioral and Social Sciences. (DTIC No. AD A219 684). Alexandria, VA.

Mayer, R. E. (2003). The promise of multimedia learning: Using the same instructional design methods across different media. Learning and Instruction, 13(2), 125139.

Miller, G.A. (1956). The magical number seven, plus or minus two. Some limits on our capacity for processing information. Psychological review, 10 (2), 343-352.

Moreno, R., \& Mayer, R. (2007). Interactive multimodal learning environments. Educational Psychology Review, 19(3), 309-326.

Rienties, B., Giesbers, B., Lygo-Baker, S., Ma, H.W.S., \& Rees, R. (2016). Why some teachers easily learn to use a new virtual learning environment: a technology acceptance perspective. Interactive Learning Environments, 24(3), 539-552.

Rogers, E. M. (2003). Diffusion of innovations (5th Ed.), New York, NY: Free.

Rose, A., Czarnolewski, M., Gragg, F., Austin, S., Ford, P., Doyle, J., \& Hagman, J.D. (1985). Acquisition and retention of soldiering skills. (671) US Army Research Institute for Behavioral \& Social Science: Arlington, VA.

Rose, A., Manning, C., Radtke, P., \& Ford, P. (1984). Acquisition and retention of soldiering skills: Report of Year 2 progress. DTIC Document.

Rose, A., Radtke, P., Shettel, H. \& Hagman, J. (1985). User manual for predicting military task retention. (AIR FR 37800)U.S. Army Research Institute for Behavioral \& Social Science: Alexandria, VA.

Sanders, W.R. (1999). Digital procedural skill retention for selected M1A2 tank intervehicular information system (IVIS) tasks. (ARI Technical Report 1096). U.S. Army Research Institute for the Behavioral and Social Sciences. Alexandria, VA. (DTIC No. ADA368212).

Sanders, W.R. (2001). Cognitive Psychology Principles for Digital Systems Training. (Research report 1773). U.S. Army Research Institute for the Behavioral and Social Sciences. Alexandria, VA. 
Sabol, M., \& Wisher, R. (2001). Retention and reaquisition of military skills. Military Operations Research. 6(1), $59-80$.

Stothard, C., \& Nicholson, R. (2001). Skill acquisition and retention in training: DSTO support to the army ammunition study. DSTO Electronics and Surveillance Research Laboratory DSTO-CR-0218. Retrieved 04.08.2016 from, https://www.researchgate.net/profile/Christina_Stothard/publication/27253778_ Skill_acquisition_and_retention_in_training_DSTO_support_to_the_army_am munition_study/links/5626cb1108aeedae57dc7c79.pdf

Swezey, R., \& Llaneras, R. (1997). Models in training and instruction. In G. Salvendy (Ed.), Handbook of Human Factors and Ergonomics (pp. 514-577). New York: Wiley.

Walker, R., Voce, J., \& Jenkins, M. (2013). Charting the development of technologyenhanced learning developments across the UK Higher Education sector: a longitudinal perspective (2001-2012). Interactive Learning Environments, 24(3) 438-455.

Walker, R., Voce, J., Nicholls, J., Swift, E., Ahmed, J., Horrigan, S., \& Vincent, P. (2014). Survey of Technology Enhanced Learning for Higher Education in the UK. Oxford: UCISA.

West, C.F., Farmer, J.A., \& Wolff, P.M. (1991). Instructional design: Implications from cognitive science. Englewood Ciffs, NJ: Prentice Hall.

Wilson, M. (2002). Six views of embodied cognition. Psychonomic Bulletin \& Review, 9, 625-636.

Wisher, R., Sabol, M., \& Ellis. J. (1999). Staying sharp: Retention of military knowledge and skills. (Final Special Report 39). US Army Research Institute for Behavioural \& Social Sciences. Alexandria, VA.

Wixted, J.T., \& Ebbesen, E.B. (1991). On the form of forgetting. Psychological Science, 2, 409-415 
Table 1. The UDA rating form (Adapted from Rose et al., 1985).

\begin{tabular}{|c|c|c|c|}
\hline UDA questions & Response & Value & $\begin{array}{l}\text { Skip } \\
\text { logic }\end{array}$ \\
\hline \multirow{2}{*}{$\begin{array}{l}\text { 1. Are job or memory aids used by the individual in } \\
\text { performing (and in the performance evaluation) this } \\
\text { task? }\end{array}$} & Yes & 1 & \\
\hline & No & 0 & $>$ Q3 \\
\hline \multirow{4}{*}{$\begin{array}{l}\text { 2. How would you rate the quality of the job or } \\
\text { memory aid? }\end{array}$} & Excellent & 56 & $>$ Q6 \\
\hline & Very good & 25 & \\
\hline & Marginally good & 2 & \\
\hline & Poor & 1 & \\
\hline \multirow[t]{4}{*}{ 3. Into how many steps has the task been divided? } & 1 step & 25 & $>$ Q6 \\
\hline & $2-5$ steps & 14 & \\
\hline & $6-10$ steps & 12 & \\
\hline & $>10$ steps & 0 & \\
\hline \multirow{3}{*}{$\begin{array}{l}\text { 4. Are the steps required to be performed in a } \\
\text { definite sequence? }\end{array}$} & None are & 10 & \\
\hline & All are & 5 & \\
\hline & Some are and some are not & 0 & \\
\hline \multirow{4}{*}{$\begin{array}{l}\text { 5. Does each task provide built-in feedback so that } \\
\text { you can tell if you are doing each step correctly? }\end{array}$} & For all steps & 22 & \\
\hline & For most steps & 19 & \\
\hline & For only a few steps & 11 & \\
\hline & No built-in feedback & 0 & \\
\hline \multirow{3}{*}{$\begin{array}{l}\text { 6. Does the task or part of the task have a time limit } \\
\text { for its completion? }\end{array}$} & No time limit & 40 & \\
\hline & Fairly easy to meet & 35 & \\
\hline & Difficult to meet & 0 & \\
\hline \multirow{4}{*}{$\begin{array}{l}\text { 7. How difficult are the mental processing } \\
\text { requirements of this task? }\end{array}$} & Almost none & 37 & $>\mathrm{Q} 10$ \\
\hline & Simple & 28 & \\
\hline & Complex & 3 & \\
\hline & Very complex & 0 & \\
\hline \multirow{4}{*}{$\begin{array}{l}\text { 8. How many facts, terms, names, rules, or ideas } \\
\text { must an individual memorize in order to do the } \\
\text { task? }\end{array}$} & None & 20 & \\
\hline & A few (1-3) & 18 & \\
\hline & Some (4-8) & 13 & \\
\hline & Very many $(>8)$ & 0 & \\
\hline \multirow{4}{*}{$\begin{array}{l}\text { 9. How hard are the facts, terms that must be } \\
\text { remembered? }\end{array}$} & Not applicable & 34 & \\
\hline & Not hard at all & 31 & \\
\hline & Somewhat hard & 12 & \\
\hline & Very hard & 0 & \\
\hline \multirow{4}{*}{$\begin{array}{l}\text { 10. What are the motor control demands of the } \\
\text { task? }\end{array}$} & None & 2 & \\
\hline & Small & 0 & \\
\hline & Considerable & 16 & \\
\hline & Very large & 3 & \\
\hline
\end{tabular}

Notes: ' ’’ denotes a response requiring a UDA question(s) to be skipped. 
Table 2. Refresher intervals and notable task characteristics for VLE organisation tasks

\begin{tabular}{|c|c|c|c|c|c|}
\hline $\begin{array}{c}\text { Task ID } \\
\left(\text { See Notes }^{1}\right)\end{array}$ & $\begin{array}{l}\text { Predicted } \\
\text { refresher } \\
\text { intervals }^{1}\end{array}$ & $\begin{array}{l}\text { Job aid } \\
\text { quality }\end{array}$ & $\begin{array}{l}\text { Procedural } \\
\text { steps to be } \\
\text { memorised }\end{array}$ & $\begin{array}{c}\text { Mental } \\
\text { processing } \\
\text { requirements }\end{array}$ & $\begin{array}{c}\text { Amended } \\
\text { refresher intervals }{ }^{23}\end{array}$ \\
\hline \multicolumn{6}{|l|}{$\begin{array}{l}\text { Slow fade } \\
\text { tasks: }\end{array}$} \\
\hline 1. & $52+$ weeks & Excellent & $\mathrm{n} / \mathrm{a}$ & Simple & $\mathrm{n} / \mathrm{a}$ \\
\hline 2. & $52+$ weeks & Excellent & $\mathrm{n} / \mathrm{a}$ & Simple & $\mathrm{n} / \mathrm{a}$ \\
\hline 3. & $52+$ weeks & Excellent & $\mathrm{n} / \mathrm{a}$ & Simple & $\mathrm{n} / \mathrm{a}$ \\
\hline 4. & $52+$ weeks & Excellent & $\mathrm{n} / \mathrm{a}$ & Simple & $\mathrm{n} / \mathrm{a}$ \\
\hline 5. & 48 weeks & Excellent & $\mathrm{n} / \mathrm{a}$ & Simple & $\mathrm{n} / \mathrm{a}$ \\
\hline \multicolumn{6}{|l|}{$\begin{array}{l}\text { Rapid fade } \\
\text { tasks: }\end{array}$} \\
\hline 6. & 15 weeks & Excellent & $\mathrm{n} / \mathrm{a}$ & Complex & $52+$ weeks \\
\hline 7. & 14 weeks & $\mathrm{n} / \mathrm{a}$ & $2-5$ & Simple & $52+$ weeks \\
\hline 8. & 14 weeks & $\mathrm{n} / \mathrm{a}$ & $2-5$ & Simple & $52+$ weeks \\
\hline 9. & 14 weeks & $\mathrm{n} / \mathrm{a}$ & $2-5$ & Simple & $52+$ weeks \\
\hline 10. & 14 weeks & $\mathrm{n} / \mathrm{a}$ & $2-5$ & Simple & $52+$ weeks \\
\hline 11. & 13 weeks & Excellent & $\mathrm{n} / \mathrm{a}$ & Complex & 48 weeks \\
\hline 12. & 13 weeks & Excellent & $\mathrm{n} / \mathrm{a}$ & Complex & 48 weeks \\
\hline 13. & 10 weeks & $\mathrm{n} / \mathrm{a}$ & $2-5$ & Simple & $52+$ weeks \\
\hline 14. & 9 weeks & Very good & $>10$ & Complex & $52+$ weeks \\
\hline 15. & 5 weeks & $\mathrm{n} / \mathrm{a}$ & $2-5$ & Complex & $52+$ weeks \\
\hline 16. & 2 weeks & $\mathrm{n} / \mathrm{a}$ & $>10$ & Complex & 16 weeks \\
\hline
\end{tabular}

Notes: ${ }^{1}$ Slow fade tasks: 1. Adding files to a page; 2. Managing page sections; 3. Making a page visible to students; 4. Displaying and hiding individual items on a page; 5. Setting up a discussion forum.

Rapid fade tasks: 6. Managing a folder on a page; 7. Adding a URL; 8. Adding a HTML page; 9. Using news forums for communications; 10. Using Quick Mail for communications; 11. Using Grademark; 12. Using Turnitin; 13. Using conditional release; 14. Adding a book activity; 15. Using completion tracking; 16 . Setting up a quiz.

${ }^{2}$ Intervals are calculated at the point at which $50 \%$ of the staff are predicted to no longer be able to perform the task successfully; $\mathrm{n} / \mathrm{a}=$ not applicable.

${ }^{3}$ Amended refresher intervals are calculated given the inclusion of a quality job aid and/or a reduction in task mental processing requirements. 


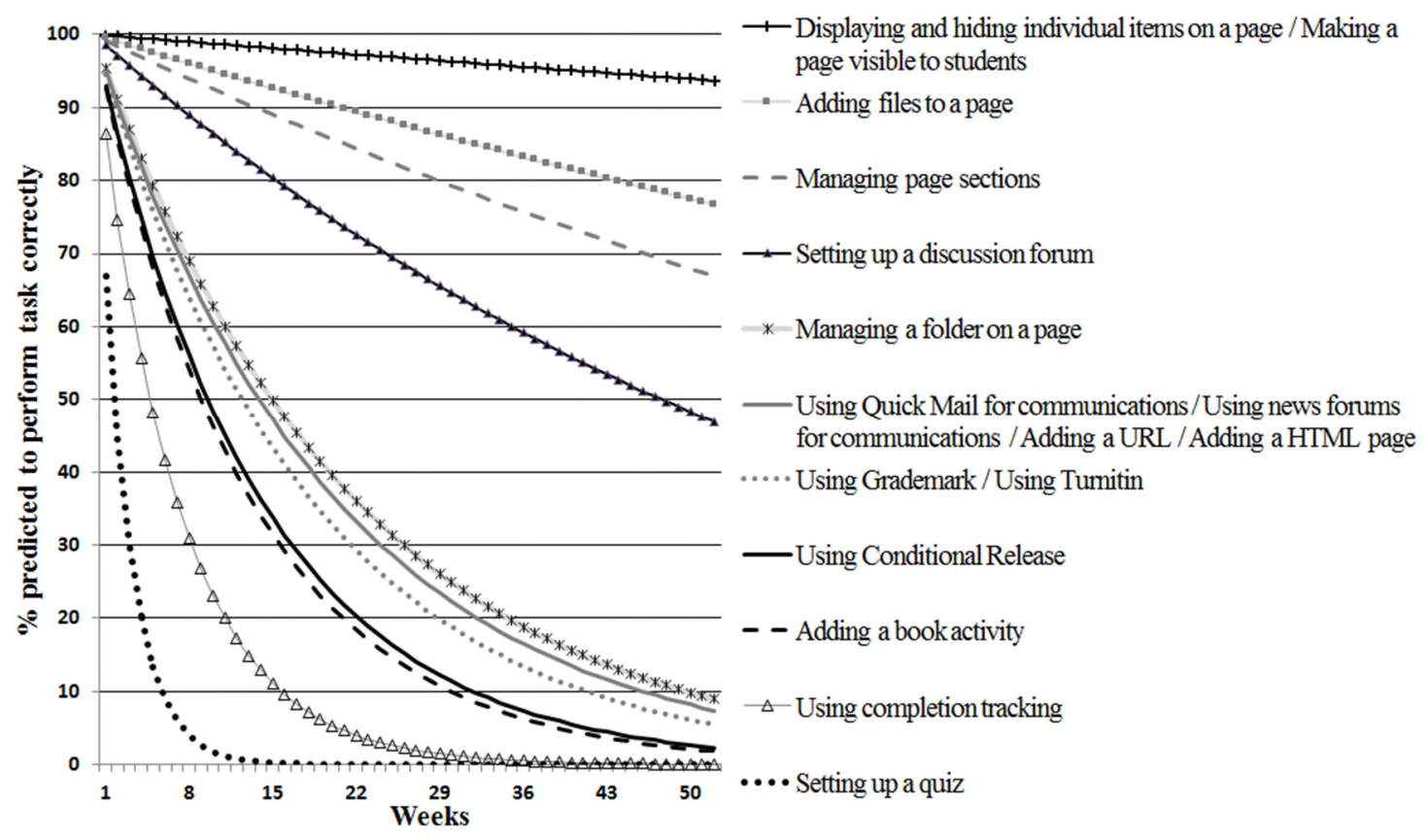

Figure 1. UDA indicative retention curves for e-learning content organisation tasks. Note the tasks displayed in the key are, from top to bottom, in the same order as the retention curves. 